\title{
Communication
}

Beauty

Definition

Idess

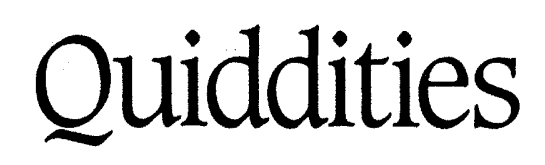

Euphemism Free Will

Creation

Gender

Language Drift

Inopredicativity

Mnowledge
Necessity

Mathematosis Truth

Negation

Paradoxes

Rhetoric

Semantic Switch

Tolerance

Universals 



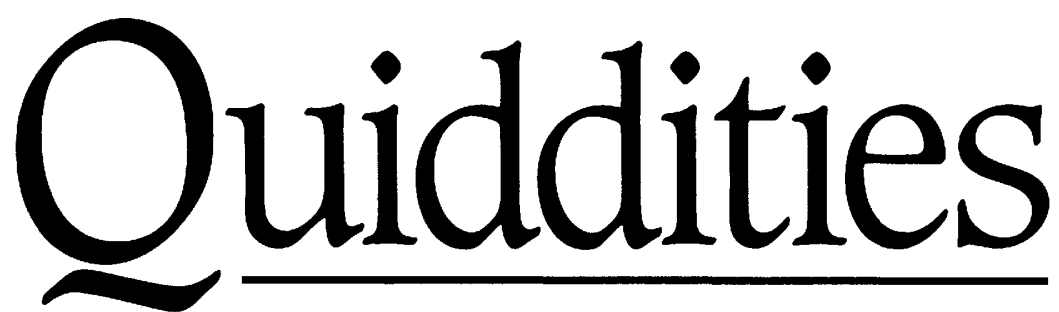

\section{An Intermittently Philosophical Dictionary}

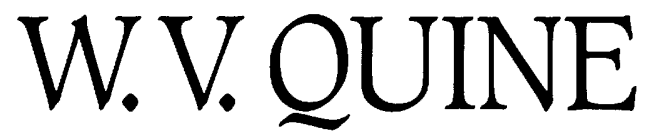

The Belknap Press of Harvard University Press

Cambridge, Massachusetts 
Copyright (C) 1987 by the President and Fellows of Harvard College All rights reserved

Printed in the United States of America

Typeset in Linotron Bembo and designed by Marianne Perlak

Library of Congress Cataloging-in-Publication Data

Quine, W. V. (Willard Van Orman)

Quiddities : an intermittently philosophical dictionary.

Includes index.

I. Philosophy-Dictionaries. I. Title.

B945.Q53Q54 $1987 \quad$ I03'.2I $^{\prime} \quad$ 87-II 974

ISBN 0-674-7435I-2 (alk. paper) (cloth)

ISBN o-674-74352-o (paper)

This book has been digitally reprinted. The content remains identical to that of previous printings. 
To three stalwart Arthrites

Frederic Cassidy

Harold Cassidy

Edward Haskell 
